\section{Forum: challenges in STD/AIDS prevention in Portuguese-speaking African countries: contributions from social research and from a gender approach. Postscript}

\author{
Fórum: desafios da prevenção das DST/AIDS \\ em países africanos de língua oficial portuguesa: \\ contribuições da pesquisa social e do recorte de \\ gênero. Posfácio
}

Richard Parker 1

For more than two decades now, the impact of HIV and AIDS has been more severe in Sub-Saharan Africa than in any other region of the world. In spite of this, both research on HIV and AIDS and program development in response to the epidemic has tended to lag behind other, far less affected regions. The legacy of colonialism and the impact of ongoing forms of imperialism have left most of the countries of Africa with limited public health infrastructures and inadequate human and financial resources with which to confront a veritable tidal wave of infectious disease that seemed to be sweeping across the continent. And in many parts of the region, these long-standing problems have been exacerbated by a more recent history of war and armed conflict that has restricted further still the possible responses to the more long-term threat posed by the growing epidemic.

Perhaps more than any other part of Africa, countries with Portuguese as their official language have suffered the effects of these various factors. Marginalized, by virtue of history and language, from many of the flows of development aid as well as from the official linguistic traditions of the intergovernmental system, when compared to Anglophone or Francophone Africa, the so-called Lusophone African countries - the African countries with Portuguese as their official language - have seen significant HIV epidemics taking shape, yet until very recently have had only limited participation in the international mobili- zation against the epidemic, and have received relatively little attention in the epidemiological and social and behavioral research literatures that have grown up around the world in response to HIV and AIDS. This Forum in the Cadernos de Saúde Pública/Reports in Public Health on the challenges of STD, HIV and AIDS prevention in Lusophone African countries, providing an overview of key research on HIV and AIDS in these countries, is therefore both timely and important in seeking to stimulate a wider research response to the epidemic.

A number of key findings from the three articles included in this Forum are worth highlighting. In her important overview article on the social science and public health literature on HIV prevention in Lusophone African countries, for example, Monteiro 1 describes a number of different issues that seem to thus far have dominated research on HIV and AIDS in these settings. On the one hand, research attention has focused on both the cultural and socioeconomic factors that have been linked to heightened vulnerability to HIV infection in specific settings: gender relations, sexuality, race and ethnicity, religion and access to health care. At the same time, research has focused on the difficulty of importing external models for HIV prevention and control, and on the difficulty of translating between the realities of international agencies, national governmental programs, and local communities. Finally, important (but still inconclusive) work 
has been done on the role of traditional healing systems, and on the impact of long-term, but often low intensity, war and armed conflict in many of the Lusophone African countries. This analysis concludes by highlighting the importance of broadening the biomedical framework that has traditionally dominated prevention policies in African societies, and introducing a new emphasis on the need to understand local cultural systems and values, and to better articulate Western biomedical models with indigenous medical systems and practices.

In their analysis of gender approaches in community-based projects aimed at responding to HIV and AIDS in Mozambique, Villela \& Barber-Madden 2 further explore one key aspect of this dilemma as they focus on contrasting conceptions of gender in official policy documents as opposed to the implementation of programs at the level of communities. In the discourse of planners and policymakers, gender highlights the dynamics of HIV vulnerability among women, highlighting the importance of transforming gender-power relationship, although largely ignoring the ways in which such relations are linked to issues of sex and sexuality. In projects developed at the community level, on the contrary, the concept of gender and concern with women's vulnerability seem to transform into actions focusing on the situations of poverty that widows (and orphans) living with HIV typically find themselves in. They highlight the difficulty of translating policy proposals into programmatic actions, especially when this act of translation involves conceptual frameworks originally developed in other cultural settings that must be adapted with great care in the specific and diverse cultural contexts found in Lusophone African countries.

In his extremely insightful analysis of the role of "tradition" in relation to both the concept of the person and the ideology of gender in Mozambique, Passador 3 takes up the complex issues related to the cultural construction of "traditional" values, locating the very definition of personhood in interpersonal and social relations (including spiritual relationships). He highlights the ways in which women's sexuality is traditionally linked to both the reproduction of kinship relations and the production of illness, especially through witchcraft and other forms of evil that destabilize social relations. This, in turn, allows him to show how easily HIV infection and AIDS can be incorporated into traditional notions of illness in Mozambique, and how medical discourses focusing on prevention, such as the $\mathrm{ABC}$ model promoted in recent years by programs supported by funding from the US government under the Bush administration, are transformed into moral discourses that conceptualize STDs, HIV, and AIDS as the result of inappropriate behaviors and socially condemned relationships. At the same time, the prevention discourse of condom use establishes itself in clear contradiction with the cultural demand for the reproduction of the kinship lineage through the conception of children, establishing a set of barriers to HIV prevention that can be confronted only to the extent that existing cultural constructions (in both "traditional" culture and "modern" HIV prevention discourses) can be deconstructed through critical analysis and reflection.

In emphasizing the importance of more detailed and locally relevant understandings of both social relations and cultural constructions in seeking to develop more effective responses to HIV and AIDS prevention and control in Lusophone African countries, the articles that make up this Forum consciously articulate an alternative vision of the kinds of issues and approaches that must be adopted in order to truly confront the epidemic. At a time when much mainstream HIV and AIDS research seems to be retreating from issues of social and cultural complexity in the name of threadbare notions of scientific "evidence" 4 , and when public health prevention and control programs seem to have abandoned health promotion strategies in favor of increasingly technocratic (and often authoritarian) alternatives 5 , the kinds of approaches that are explored here offer hope that perhaps many of the most important insights into the social, cultural, political and economic dimensions of HIV and AIDS that were learned during the first 25 years of the epidemic not only will not be lost in the recent rush toward simple solutions and magic bullets, but that these insights will themselves be extended through innovative new investigation and action taking place in regions and countries that until recently had received inadequate attention.

While these various considerations are all clearly articulated in the three main articles in this Forum, there are also a number of other conclusions - particularly in relation to research development and research infrastructures - that are perhaps more implicit, but that are worth highlighting here explicitly. When one looks historically at the literature reported in this Forum, there seems to be an important trend taking place over time in the kind of research that is being done in response to the epidemic, in who is doing the research, and on the process of building a critical mass of trained scientists and research institutions to be able to carry forward such work in the future. Many of the earliest studies relevant to HIV and AIDS in Lusophone African countries (as 
in other parts of sub-Saharan Africa) appear to have been carried out by foreigners - particularly by researchers from North America or Western Europe, sometimes but not always in collaboration with local investigators. While these studies may in some cases have provided results that were potentially useful in seeking to understand and respond to the epidemic, their local impact appears to have been relatively limited, perhaps at least in part because their publication in international scientific research venues (dominated by English as the primary language of contemporary scientific communication) may well have limited access to their results at a more local or even national level.

There clearly seems to be a more recent, second wave of research - a wave that the articles in this Forum both report on and participate in - that has been built up through the rise of what has been described as "horizontal cooperation" in response to the HIV epidemic. In this second wave, collaboration between African countries has grown in importance in a variety of ways, including through cooperative research undertakings (for example, studies undertaken in Mozambique by investigators from that country working in collaboration with investigators from South Africa) as well as through capacity-building resulting from exchanges within the continent (for example, researchers from Mozambique trained in universities from countries such as South Africa who return to live and work in Mozambique).
While these kinds of inter-African exchanges appear to still be relatively limited, they nonetheless offer important hope for the growth of a greater local research infrastructure in the future. Parallel to them, however, it is also possible to witness the rise of a significant level of horizontal cooperation between Brazilian researchers and public health specialists working with counterparts from Lusophone African countries. This growing research focus, carried out in Portuguese and increasingly published both in Portugueselanguage scientific venues as well as in Englishlanguage venues, marks an especially important trend that seems likely to reshape the nature of HIV and AIDS research in Lusophone Africa in the future.

The gradual history of research development in response to HIV and AIDS that is reported here in this Forum on challenges of HIV/AIDS prevention in Lusophone African countries suggests that, as much as the response to the epidemic through concrete programmatic actions, the research response to HIV and AIDS is also socially and historically constructed - and that its construction requires effective and meaningful collaboration over time and across cultures. This Forum is itself a part of this process of construction, with specific relation to Lusophone Africa. It is part of an on-going process of research development that is of crucial importance as we seek to more effectively respond to HIV and AIDS in the future.

\section{References}

1. Monteiro S. STD/AIDS prevention in Portuguesespeaking Africa: a review of the recent literature in the social sciences and health. Cad Saúde Pública 2009; 25:680-6.

2. Villela WV, Barber-Madden R. The gender approach in community AIDS projects in Mozambique: agreement and disagreement between government and civil society. Cad Saúde Pública 2009; 25:694-9.

3. Passador LH. "Tradition", person, gender, and STD/HIV/AIDS in southern Mozambique. Cad Saúde Pública 2009; 25:687-93.
4. Potts M, Halperin DT, Kirby D, Swidler A, Marseille E, Klausner JD, et al. Public heath. Reassessing HIV prevention. Science 2008; 320:749-50.

5. Granich RB, Gilks CF, Dye C, De Cock K, Williams BG. Universal voluntary HIV testing with immediate antiretroviral therapy as a strategy for elimination of HIV transmission: a mathematical model. Lancet 2008; 373:48-57.

Submitted on 28/Jan/2009

Approved on 30/Jan/2009 